\title{
Análise conjuntural do comércio exterior da floricultura brasileira
}

\author{
ANTONIO HÉLIO JUNQUEIRA(1) e MARCIA DA SILVA PEETZ(2)
}

As exportações brasileiras de flores e plantas ornamentais somaram, em 2009, US\$ 31,137 milhões, valor que representou uma queda substancial de $12,30 \%$ em relação ao desempenho do ano anterior.

Tal resultado era aguardado, tendo em vista os efeitos da crise econômica e financeira internacional que abalou sensivelmente os principais mercados importadores da floricultura nacional, como os EUA, os países da União Européia e o Japão.

Há que se notar que a retração internacional da demanda já havia começado a se manifestar na balança comercial da floricultura brasileira desde a deflagração da crise no mercado norte-americano, a partir de setembro de 2008. De fato, naquele ano, a desaceleração dos embarques ao longo do último trimestre fez com que o resultado das exportações anuais crescesse apenas $0,64 \%$ sobre 2007, invertendo a tendência de desempenho bem mais pujante que vinha caracterizando o setor ao longo de toda a última década ${ }^{(3)}$.

Os resultados menores não alteraram, contudo, o perfil exportador nacional, o qual foi liderado pelo setor de bulbos, tubérculos e rizomas em repouso vegetativo (com participação de $45,65 \%$ sobre o total), seguido pelo de mudas de plantas ornamentais $(41,55 \%)^{(4)}$. Aliás, deve-se lembrar que esta característica estrutural do comércio exterior da floricultura brasileira, qual seja a de concentrar-se na venda de produtos destinados à propagação vegetativa, foi o que impediu uma queda ainda mais acentuada nas suas exportações. Países vizinhos, como Colômbia, Equador e Costa Rica, cuja pauta do comércio exterior florícola é essencialmente sustentada pelas flores e folhagens frescas para corte, ressentiram-se das retrações da demanda mundial em escala efetivamente dramática.

Particularmente neste segmento de produtos frescos para consumo final observaram-se, também para o Brasil, quedas importantes na venda exterior de rosas $(-50,08 \%)$ e de outras flores de corte $(-35,48 \%)$. Contudo, para o setor de maneira geral, a vantagem foi que tais itens, comprovadamente mais sensíveis à retração da demanda global, representam uma parcela pequena na balança comercial do País, o que, de certa maneira, minimizou os efeitos recebidos da retração mundial.

\section{SETOR DE BULBOS, TUBÉRCULOS E RIZOMAS EM REPOUSO VEGETATIVO(5)}

Esse segmento fechou o ano de 2009 com vendas totais de US\$ 14,214 milhões, o que representou uma queda de 9,90\% em relação ao ano anterior. Tendo como principais produtos de exportação os bulbos de gladíolos (Gladiolus sp), de lírios (Lilium sp) e de amarílis (Hippeastrum sp.), entre outros similares, o segmento exportou os seus produtos para: Holanda $(86,21 \%)$, EUA $(12,56 \%)$, Canadá $(0,77 \%)$, Chile $(0,26 \%)$, México $(0,14 \%)$ e Uruguai $(0,06 \%)$. As quedas no comércio exterior desses itens, comparativamente a 2008, foram sentidas em relação a todos os destinos, com exceção apenas do mercado norte-americano, no qual experimentou uma expansão de $22,00 \%$. Tais retrações nas vendas foram mais expressivas para o México $(-78,84 \%)$ e Canadá $(-34,86 \%)$. Acabaram não ocorrendo, também, as tradicionais exportações, ainda que em pequenos volumes, para a Dinamarca, Itália e Alemanha.

Além do item analisado no parágrafo anterior, a exportação global do setor de bulbos, tubérculos e rizomas se completa com os resultados do grupo desses propágulos vendidos já na sua fase vegetativa ${ }^{(6)}$. Neste caso, os resultados são bem mais modestos, tendo somado, em 2009, o total de US\$ 211,20 mil, com crescimento de 19,34\% sobre o ano anterior. Os destinos destas mercadorias foram: Holanda $(69,77 \%)$, Índia $(16,31 \%)$, Hong Kong $(4,98 \%)$, Alemanha $(4,55 \%)$, China (2,13\%), Indonésia $(0,98 \%)$, Japão $(0,63 \%)$, EUA $(0,44 \%)$ e Espanha (0,22\%).

\footnotetext{
${ }^{(1)}$ Engenheiro agrônomo, mestre em Comunicação e Práticas de Consumo (ESPM), pós-graduado em Desenvolvimento Rural e Abastecimento Alimentar Urbano (FAO/PNUD/CEPAL/IPARDES), sócio administrador da Hórtica Consultoria e Treinamento.

(2) Economista, pós-graduada em Comercialização Agrícola e Abastecimento Alimentar Urbano, sócia-administradora da Hórtica Consultoria e Treinamento.

(3) É importante ressaltar, contudo, que o ritmo de crescimento das exportações manteve-se mais intenso na primeira metade da década $2000-2009$. A partir de 2007, frente aos persistentes movimentos de valorização cambial do real frente ao dólar, constatou-se certo arrefecimento no desempenho do comércio exterior da floricultura do País.

${ }^{(4)}$ Afloricultura exportadora do Brasilhistoricamenteéliderada pelo setorprodutor demudas deplantas ornamentais. No entanto, pormotivos conjunturais diversos, em alguns momentos específicos, este chega a ser suplantado pelos melhores resultados obtidos pelo segmento de bulbos, tubérculos e rizomas em repouso vegetativo. Foi o que aconteceu, porexemplo, no ano de 2008, no qualo setordebulbos representou44,44\% do total o de mudas $41,23 \%$. Em 2009 , como sevê, tal ordem veio a se repetir no ranking dos setores.

(5) Código NCM (Nomenclatura Comum do MERCOSUL) 06011000: Bulbos, Tubérculos, Rizomas etc. em Repouso Vegetativo.

${ }^{(6)}$ Código NCM (Nomenclatura Comum do MERCOSUL) 06012000: Bulbos, Tubérculos etc., em Vegetação, em Flor e Mudas de Chicórea.
} 
Os bulbos exportados pelo Brasil em 2009 tiveram como origem os Estados de São Paulo (75,83\%) e Ceará $(24,17 \%)$. Os produtos paulistas seguiram prioritariamente para a Holanda $(91,28 \%)$ e, em segundo plano, para os EUA $(8,12 \%)$, Chile, México e Uruguai. Os bulbos cearenses, por sua vez, foram dirigidos para a Holanda (70,31\%), EUA $(26,49 \%)$ e Canadá $(3,21 \%)$.

\section{MUDAS DE PLANTAS ORNAMENTAIS ${ }^{(7)}$}

Esse segmento acumulou, em 2009, vendas exteriores de US\$12,938 milhões, com decréscimo de $11,60 \%$ em relação ao ano anterior. O setor foi liderado pelas estacas de crisântemos (Chrysanthemum sp), seguidas de outras mudas sem raiz ou de raiz nua, tais como as de violetas (Saintpaulia ionnantha), begônias (Begonia elatior), espatifilo (Spathiphyllum sp.) e comigo-ninguém-pode (Dieffenbachia sp.), entre outras. Participaram do segmento outras mudas produzidas em torrões de substratos estéreis, como antúrios, calatéias, marantas e forrações diversas.

Os principais destinos desses produtos no ano passado foram: Holanda (37,70\%), EUA (26,51\%), Itália (18,89\%), Bélgica (5,57\%), Japão (3,58\%), Polônia (1,77\%) e Canadá $(1,37 \%)$, além de 21 outros países importadores. Entre os principais parceiros comerciais, as maiores reduções das exportações foram observadas para o Canadá $(-37,41 \%)$, Japão (-27,99\%), Argentina (-27,95\%), Holanda (-22,11\%), EUA (-11,68\%) e Bélgica (-11,54\%). Por outro lado, o setor experimentou crescimento de vendas para a Polônia $(259,69 \%)$, Reino Unido (85,98\%), Alemanha $(23,20 \%)$ e Itália $(9,75 \%)$.

As mudas de plantas ornamentais brasileiras exportadas foram produzidas nos Estados de São Paulo (74,74\%), Rio Grande do Sul (21,83\%), Santa Catarina (2,54\%), Ceará $(0,72 \%)$, Distrito Federal $(0,11 \%)$ e Rio de Janeiro $(0,05 \%)$. É interessante observar que enquanto os produtos paulistas seguiram prioritariamente para Holanda (46,63\%), EUA $(35,26 \%)$, Bélgica $(7,45 \%)$ e Japão $(4,79 \%)$, as mudas gaúchas foram exportadas para Itália $(86,30 \%)$ e Polônia $(8,09 \%)$. O destino italiano deveu-se ao fato de estar localizada naquele país a sede da Lazzeri Agricultural Group, matriz à qual se filia a maior unidade produtora e exportadora brasileira de mudas do Rio Grande do Sul, na cidade de Vacaria.

\section{MUDAS DE ORQUÍDEAS ${ }^{(8)}$}

O segmento experimentou um crescimento de $9,05 \%$ em relação a 2008, somando um valor total de exportações de US \$ 219,86 mil. Os principais países de destino foram: Japão $(53,08 \%)$, Alemanha $(21,74 \%)$, EUA $(12,27 \%)$ e Holanda (8,08\%), além de Ucrânia, Taiwan, Hong Kong, África do Sul e Chile. O Japão transformou-se no principal cliente desse setor específico da floricultura, com um crescimento de $242,23 \%$ sobre as importações do ano anterior. Constatou-se, ainda, abertura comercial em outros destinos não tradicionais como a Ucrânia e a África do Sul.

Vale lembrar que o florescente setor exportador brasileiro de mudas de orquídeas não está baseado na exploração industrial de híbridos comerciais - caracterizados por plantas produtoras de longos cachos repletos de flores de grandes dimensões -, como o fazem os principais exportadores mundiais do segmento, como Tailândia e Holanda, entre outros. Pelo contrário, no caso nacional, os produtos exportados são espécies nativas e seus híbridos, destinados especialmente ao mercado de colecionadores. Trata-se, portanto, de um mercado de nichos, onde as pequenas quantidades ofertadas são compensadas pelos melhores níveis de preços unitários obtidos pelas mercadorias.

\section{OUTRAS MUDAS}

As exportações globais do setor de mudas se complementaram com as vendas externas de outras mercadorias agrupadas em diferentes códigos NCM, quais sejam as de mudas de outras plantas ${ }^{(9)}$, rododendros e azaléias enxertados ou não ${ }^{(10)}$, estacas não enraizadas e enxertos $^{(11)}$ e outras plantas vivas ${ }^{(12)}$. No total, todos esses grupos agregaram um valor adicional de exportações de US\$ 313,37 mil, com crescimento de $21,03 \%$ sobre o ano de 2008.

\section{FLORES FRESCAS DE CORTE E SEUS BOTÕES ${ }^{(13)}$}

O Brasil não é, historicamente, um player importante no mercado mundial de exportações de flores frescas de corte. Apesar disto, o País chegou a experimentar períodos de bons desempenhos neste segmento, notadamente entre os anos de 2003 a 2007, nos quais o setor foi puxado essencialmente pelas importações do mercado norte-americano. Com a instauração e aprofundamento da crise econômica e financeira recente - primeiro naquele país, a partir de setembro de 2008, e com posterior alastramento pela Europa e Ásia -, o setor perdeu fôlego e veio a sofrer quedas consideráveis nos volumes embarcados. De fato, em 2009, o valor comercializado atingiu

\footnotetext{
(7) Código NCM (Nomenclatura Comum do MERCOSUL) 06029029: Mudas de Outras Plantas Ornamentais.

(8) Código NCM (Nomenclatura Comum do MERCOSUL) 06029021: Mudas de Orquídeas.

(9) Código NCM (Nomenclatura Comum do MERCOSUL) 06029089: Mudas de Outras Plantas.

(10) Código NCM (Nomenclatura Comum do MERCOSUL) 06023000: Rododendros e Azaléias, Enxertados ou Não.

(11) Código NCM (Nomenclatura Comum do MERCOSUL) 06021000: Estacas NãoEnraizadas e Enxertos.

${ }^{(12)}$ Código NCM (Nomenclatura Comum do MERCOSUL) 06029090: Outras Plantas Vivas.

${ }^{(13)}$ Somatória dos produtos agregados pelos Códigos NCM (Nomenclatura Comum do MERCOSUL) 06031000: Flores e seus Botões, Frescos, Cortados, p/Buquês etc.; 06031100: Rosas e seus Botões, Cortados, p/Buquês, e Ornamentações, Frescos; 06031400: Crisântemos e seus Botões, Cortados, p/Buquês e Ornamentações, Frescos; 06031300: Orquídeas e seus Botões, Cortados, p/Buquês e Ornamentações, Frescos e 06031900: Outras Flores e seus Botões, Cortados, p/Buquês e Ornamentações, Frescos.
} 
apenas US\$ 1,444 milhão, com queda de 39,45\% sobre o ano anterior.

Para as flores de corte em geral - que incluem lírios, gérberas, antúrios, lisitantus, celósias e flores tropicais, entre outras - os principais destinos importadores foram: EUA (38,74\%), Holanda (36,42\%), Portugal (13,77\%), Chile (5,66\%) e Canadá (4,29\%), seguidos de Angola, Alemanha, Bolívia, Cabo Verde e Itália. Especificamente para as rosas, com vendas globais de US\$ 353,44 mil (e queda de 50,08\% em relação a 2008), os principais destinos foram: Holanda $(66,86 \%)$ e Portugal $(31,61 \%)$, além de Cabo Verde e Azerbaijão. Já as orquídeas cortadas foram enviadas exclusivamente para o Uruguai e os crisântemos, para Cabo Verde.

\section{FLORES SECAS ${ }^{(14)}$}

O setor exportou um total de US\$ 44,56 mil, o que representou uma queda de $9,61 \%$ em relação ao ano de 2008. Os principais destinos constituíram-se na Alemanha $(36,68 \%)$, Holanda $(28,10 \%)$, Argentina $(25,19 \%)$, além de Senegal, China e Itália.

\section{BALANÇA COMERCIAL DA FLORICULTURA BRASILEIRA}

Em 2009, a balança comercial da floricultura brasileira obteve saldo de U\$ 11,323 milhões, um dos menores resultados da última década (Ver Tabela na página seguinte). Por outro lado, o perfil importador estrutural do Brasil não mostrou alterações importantes, mantendo a caracterização do País como comprador internacional de material básico vegetal para propagação e posterior re-exportação.

De fato, o principal item da pauta de importações continuou sendo representado pelos bulbos, tubérculos, rizomas e similares, em repouso vegetativo (41,69\%), seguido por mudas de outras plantas $(15,15 \%)$, mudas de orquídeas $(14,62 \%)$ e mudas de outras plantas ornamentais $(12,07 \%)$.

No segmento das flores e plantas importadas diretamente para consumo, o maior destaque ficou, como de costume, para as rosas frescas de corte $(11,55 \%)$, oriundas principalmente da Colômbia. No ranking, seguiram as outras flores frescas de corte em geral $(2,41 \%)$ e os cravos $(1,01 \%)$.

\section{PERSPECTIVAS PARA 2010}

A floricultura brasileira detém a enorme vantagem de ser focada essencialmente no suprimento do mercado interno, para o qual dirige a quase totalidade de sua produção $(97,78 \%$ do valor comercializado em 2009). Tal fato vem permitindo que o setor opere com tranqüilidade no contexto da forte crise econômica e financeira mundial, sorte essa não experimentada pelos vizinhos países de economia florícola exportadora, como a Colômbia, Costa Rica e Equador.

Essa característica é, de fato, alentadora, visto que as condições de recuperação dos mercados importadores nos EUA, União Européia e Japão deverão ainda tardar. Frente a esse quadro global, as projeções para as exportações das flores e plantas ornamentais brasileiras - ainda que prematuras - são conservadoras. Como apontado ao longo desse balanço, embora, por um lado não se projetem recuperações comerciais imediatas, por outro também não se espera que o Brasil aprofunde ainda mais as quedas de suas vendas. Conforme observado, o perfil exportador nacional não está focado no segmento consumidor final dos países de destino, mas sim no segmento produtivo, para o qual envia materiais propagativos básicos para terminação vegetativa e floração. Portanto, os efeitos da crise, ainda que não ignoráveis, tenderão a produzir impactos menos intensos.

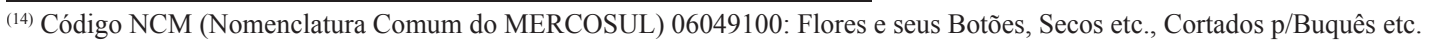

